\title{
UNDERSTANDING INDUSTRY 4.0: DEFINITIONS AND INSIGHTS FROM A COGNITIVE MAP ANALYSIS
}

Guilherme Brittes Benitez guilherme.benitez@hotmail.com Federal University of Rio Grande do Sul - UFRGS, Porto Alegre, Rio Grande do Sul, Brazil.

Mateus José do Rêgo Ferreira Lima

mateusjose30@gmail.com

Federal University of Rio Grande do Sul - UFRGS, Porto Alegre, Rio Grande do Sul, Brazil.

Laura Visintainer Lerman lauravlerman@gmail.com Federal University of Rio Grande do Sul - UFRGS, Porto Alegre, Rio Grande do Sul, Brazil.

Alejandro Germán Frank frank@producao.ufrgs.br Federal University of Rio Grande do Sul - UFRGS, Porto Alegre, Rio Grande do Sul, Brazil.

\section{ABSTRACT}

Goal: The purpose of this paper is to present an analysis of Industry 4.0 concepts and technologies through the lens of practitioners and scholars with considerable expertise in this field.

Design / Methodology / Approach: A qualitative research was conducted based on seven semi-structured interviews guided by an open questionnaire, which was developed with the main goal of understanding the concept of Industry 4.0 and the technologies that compose this industrial phenomenon.

Results: Based on this methodology, a cognitive map is presented as the result and final product of this study. This cognitive map is composed of five different clusters, each one represented by different colors, which relate to each of the questions in the questionnaire. Our analysis provides a better understanding of (i) the main concepts of Industry 4.0; (ii) the implementation stages for companies; (iii) the main enabling technologies; (iv) the concept of M2M (machine-to-machine); and (v) the scenario in Brazil. Each one of the clusters enables a discussion by bringing what is in the literature on the topic.

Limitations of the investigation: The main limitations of the article are found in the subjectivity of the results and also in the scarcity in the literature related to some topics covered in the clusters.

Practical implications: This research can be potentially useful for practitioners, since it sheds light on the Industry 4.0 concept and how technologies are used to integrate processes.

Originality / Value: The clusters answers of the cognitive map allowed comparisons with the literature and a discussion about Industry 4.0, making it possible to direct and check gaps in the research.

Keywords: Industry 4.0 concepts; Industry 4.0 technologies; semi-structured interviews; cognitive map analysis. 


\section{INTRODUCTION}

Information is a set of organized data, which constitutes a message about a particular event or phenomenon. The level of information captured as well as the manner in which it will be interpreted and used are crucial factors for decision-making within organizations (Chung and Kim, 2016). However, the recognition of what is valuable and robust information among a large pool of useless and superficial data remains a problem within companies. Acquiring a significant amount of information about a particular subject and determining what pieces are relevant constitutes a difficulty that organizations have to face (Shaabany et al., 2016). In this sense, data science has recently emerged as a way to support decision makers in assessing the usefulness of information by how often words or data on a particular subject are available (Nelson et al., 2001).

Taking this difficulty into account, the 4th Industrial Revolution appears as a solution and an opportunity to increase competitiveness and productivity for companies (Jeschke et al., 2017). The 4th Industrial Revolution, also known as Industry 4.0, has as its starting point the connectivity and the complete availability of information for all actors within the organizations through concepts such as the Internet of Things, cyber-physical systems and cloud computing (Gilchrist, 2016; Jeschke et al., 2017). These concepts are based on the premise of the connectivity between the physical and digital elements as well as the decentralized decision-making of the machines from the information captured and processed by them in real time (Brettel et al., 2014; Herman et al., 2016). However, some questions about the origins of this new industrial phenomenon and its technologies still puzzle a number of scholars and consulting firms. In fact, many studies have been conducted and published about the operability of Industry 4.0 technologies and how it enhances industrial performance (e.g. Dalenogare et al., 2018), while the lack of definitions regarding Industry 4.0 allows for discussion, as pointed out by several authors (e.g. Jazdi, 2014; Lasi et al., 2014; Möller, 2016; Bartodziej, 2017).

Hence, the purpose of this article is to shed light on the following questions: What is Industry 4.0 and what are its main technologies? To answer these questions, a questionnaire was elaborated and semi-structured interviews were carried out with different specialists of the Industry 4.0 field, ranging from managers to full-time professors. After the interviews had been conducted, the data was analyzed and interpreted. The product of this investigative process is a cognitive map, which aims to represent the perception of the individuals involved in the research about Industry 4.0 concepts and technologies.

The remaining sections of this paper are organized as follows. First, the theoretical background is introduced (Sect.
"Theoretical Background") to the main topic point of this analysis, the Industry 4.0. In this section, the main aspects of this industrial phenomenon, its origins, main definitions, and how it is seen across countries are explained. After this, the methodological procedures used in this paper are detailed (Sect. "Research method"). In Sect. "Results" the results are presented with the most mentioned words identified from the interview and the cognitive map proposed. Finally, Sect. "Discussions" contains a discussion of the results found using the literature and search directions, while Sect. "Conclusions" brings a summary and this paper's final remarks.

\section{THEORETICAL BACKGROUND}

The term "Industry 4.0" emerged at the Hannover Messe technology trade fair in Germany in 2011. However, the first report on the subject was only released in 2013 by Acatech $^{\circledR}$, a German science academy, about recommendations of good practices and recommendations for the implementation of Industry 4.0 technologies for the German government. Industry 4.0 is an initiative of the German government that aims to implement strategies focused on technology. The term has been strengthened worldwide and has been debated by many German authors (Brödner, 2015; Dregger et al., 2016; Zimmermann et al., 2016). Nevertheless, while the German government worked on consolidating a terminology for the profusion of these new industrial technologies, the United States, in contrast, worked on the term "Advanced Manufacturing" for years, not accepting the German term proposed in 2011.

Whether it is labelled as Industry 4.0 or Advanced Manufacturing, the objective is essentially the same in the industrial scenario: acquire, separate, and order information to increase productivity and competitiveness (Goreck et al., 2014; Schuh et al., 2014). For this purpose, Industry 4.0 offers the integration of existing technologies/tools (embedded systems, sensors, actuators, and others) to provide connectivity, capturing and data processing in real time. Among the technologies/tools mentioned in the reports and articles, the authors point to servers (cloud computing), autonomous robots, additive manufacturing (3D printer), virtual reality, augmented reality, simulation, and cyber security as potential enablers for the creation of smart factories (Jazdi, 2014; Lasi et al., 2014; Möller, 2016; Bartodziej, 2017).

Through these technologies/tools and the standardization of industrial protocols for machines to communicate, authors such as Jansen and Cusumano (2013), Trappey et al. (2017) and Ferreira et al. (2016) say that vertical plant integration is possible. This is the connectivity link for machines and equipment to work integrated within the manufacturing environment (Marques et al., 2017). With vertical integration, data would be available and organized in a cloud where 
Brazilian Journal of Operations \& Production Management

Volume 16, Número 2, 2019, pp. 192-200

DOI: 10.14488/BJOPM.2019.v16.n2.a3 users would work with an interface in which they could take what is necessary for strategic decision-making (Jeschke et al., 2017). Thus, it would be possible to move towards horizontal integration, which consists of the link between other actors (suppliers, put sourced companies, clients) of the value chain. Horizontal integration in the context of Industry 4.0 is represented by the integration of the value chain to generate, achieve, and process real-time information from both processes and systems, from the purchase of raw material to the delivery of the final product to the customer (Zhou et al., 2015).

Considering the possibility that organizations may reach an advanced level of data processing and analysis from vertical and horizontal integration and enabling technologies for this purpose, Industry 4.0 also makes reference to end-toend engineering (Posada et al., 2015). This term designates organizations capable of monitoring raw material transport to final product use (Wang et al., 2016). This generates value for both the firm - that can monitor the performance of its product and re-plan its design and functionalities-and the customer, who receives a service from the firm (Wang et al., 2016). Therefore, all these possibilities are enabled by technologies, tools, and the standardization of industrial protocols of machines and equipment, creating a 4.0 environment within the organization.

\section{METHODOLOGY AND DATA COLLECTION}

The research is exploratory and descriptive (Lee et al., 2002; Lambert and Lambert, 2012), seeking to understand the theme "Industry 4.0" from semi-structured interviews (Harrell and Bradley, 2009). Figure 1 describes the methodological steps of this article. The steps were organized in 3 main phases: "Fieldwork", "Data stratification," and "Results."

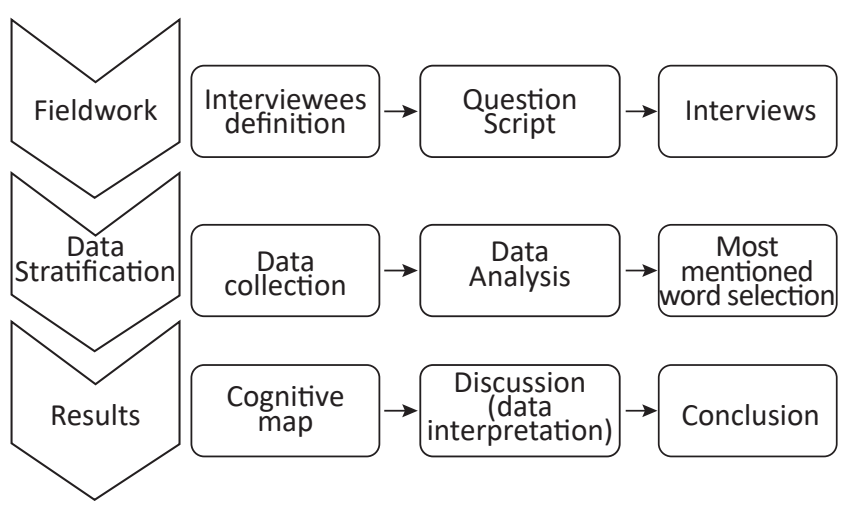

Figure 1. Methodological procedures Source: The authors.

The methodology begins at the "Fieldwork" phase with the definition of the interviewees. Table 1 shows the list of respondents, their profile, and the type of company / entity they are part of.

Table 1. Interviewee's list

\begin{tabular}{ccc}
\hline No & Interviewee & Company/Entity \\
\hline 1 & Director & Automotive company \\
\hline 2 & CEO & Technological services provider \\
\hline 3 & $\begin{array}{c}\text { Professor Dr. } \\
\text { of Mechanical } \\
\text { Engineering }\end{array}$ & $\begin{array}{c}\text { UFRGS - Universidade Federal } \\
\text { do Rio Grande do Sul }\end{array}$ \\
\hline 4 & $\begin{array}{c}\text { Professor Dr. } \\
\text { of Electrical } \\
\text { Engineering }\end{array}$ & $\begin{array}{c}\text { UFRGS - Universidade Federal } \\
\text { do Rio Grande do Sul }\end{array}$ \\
\hline 5 & CEO & Systems and software provider \\
\hline 7 & Manager & $\begin{array}{c}\text { Former employee of large } \\
\text { company providing digital } \\
\text { services and technologies }\end{array}$ \\
\hline & Engineer & $\begin{array}{c}\text { Company that provides } \\
\text { technologies and sensors }\end{array}$ \\
\hline
\end{tabular}

Since the number of research on the subject is not pronounced (Pereira et al., 2018), this work sought to understand this field of study field from the perspective of professionals as well as the reasons behind their perception (Nadae and Carvalho, 2017; Veiga et al., 2011). Therefore, at the beginning of 2017, the interviews were conducted to lead to an understanding of 14.0's role and definition-and what technology is used. The selection criteria of those interviewed were established based on the potential of contribution that the interviewees could provide for qualitative research. For instance, interviewee 1 was selected because of his company's interest in becoming a 4.0 factory. Interviewee 2 was selected by his company to provide technological services, installing software and systems. Interviewees 3 and 4 were selected because they are full-time professors who have expertise in embedded systems and automation technologies.

Interviewee 5 was selected because he is the CEO of a company that has been offering systems and software for more than 10 years. Interviewee 6 was a manager in a large company that provides digital services and technologies. Finally, interviewee 7 was selected because he is the engineer of a company that supplies technologies and sensors for large companies. Once the interviewees had been selected, the questionnaire was established. Table 2 presents the questions interviewees were asked.

The purpose of the interviews was to understand the role of 14.0: what is Industry 4.0 definition from the interviewees' perspective, asking about steps that a firm should follow to achieve the status of an 14.0 factory. In addition, they were asked about their perception of 14.0 in the Brazilian context, a middle-income country, and what is the technology do- 
main necessary to be an 14.0 factory. Moreover, they were asked about M2M.

Consequently, five questions were defined based on the discussions that the literature contains about the Industry 4.0. The first one is a more general question, aiming to establish what interviewees understand about the topic. The second and third questions seek to understand the interviewees' degree of knowledge on the subject. Moreover, these are questions that many authors have been discussing since 2011, when the name Industry 4.0 was created, and the first report was published in 2013 (Kagermann et al., 2013). The fourth question seeks to understand the interviewees' knowledge about communication between the machines, also a topic that has been largely discussed in the literature and known as machine to machine (M2M) (Wan et al., 2015; Gilchrist, 2016). Lastly, the fifth question aimed to obtain an understanding of the scenario in Brazil based on the interviewees' opinions from the understanding of the barriers that may arise or already exist.

Table 2. Question script

\begin{tabular}{c}
\hline Question script \\
\hline 1. What do you understand as Industry 4.0? \\
\hline $\begin{array}{c}\text { 2. If a company requested to become } 4.0 \text { through steps } \\
\text { (due to lack of investment), what would the steps be? }\end{array}$ \\
\hline 3. What are the minimum technologies that one \\
must have in order to have a 4.0 industry? \\
4. What do you understand about \\
communication between machines?
\end{tabular}

5. In your opinion, are Brazilian companies prepared for industry 4.0 or are there difficulties? What are the barriers? Source: The authors.

After the question script was defined, the interviews were carried out, and the dialogues were recorded. In the "Data Stratification" phase, the collected data was transcribed to verify the similarities of the respondents' answer regarding the topic. The data was analyzed and interpreted through WordArt, generating the most mentioned word relation in the interviews. Finally, the "Results" phase was conducted.

From the interpretation of the words generated by WordArt $^{\circledR}$, and with the help of GoConqr ${ }^{\circledR}$, a cognitive map was created to represent the understanding of the theme based on the respondents' answers. A cognitive map, according to Bougon (1983), is a term generically used to represent possible patterns of relation between concepts and opinions of different specialists. It is, essentially, a technique that is used to map the thinking of individuals or groups of people who debate themes based on their subjective views and beliefs about the same subject (Bastos, 2002; Guimarães, 2007). After the creation of the cognitive map, five clusters of words were generated. Each cluster answers each question of the script created by the authors. The main aspects perceived were responsible to point directions for future research.

\section{RESULTS}

After the transcription of the seven interviews, a total of 91 pages was obtained on Microsoft Word. In order to match respondents' answers, WordArt ${ }^{\circledR}$ provided an overview of the key words mentioned. Figure 2 shows the relationship of the main words mentioned in the interviews.

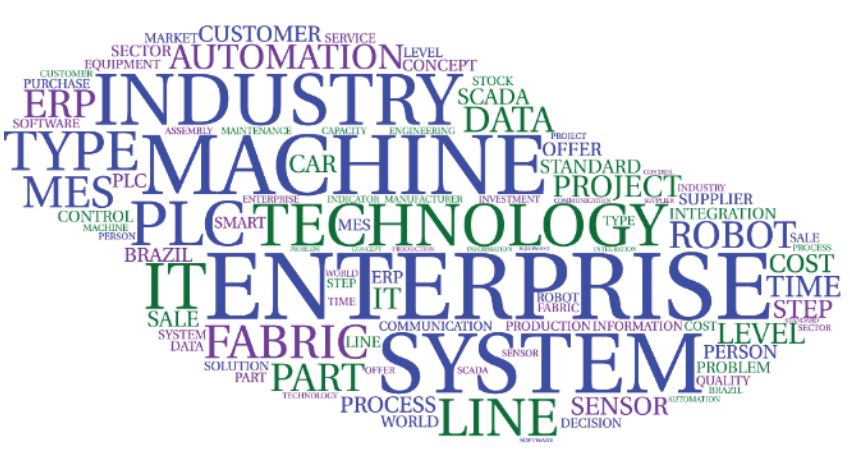

Figure 2. Most mentioned words Source: The authors.

Three criteria were adopted for the words selection: (i) a minimum of 20 mentions; (ii) elimination of common words, such as: "thus", "but", and (iii) sum of synonyms, for example: "integration," "integrate," and "integrated" for a single word. The larger the word, the more often it was quoted in the transcripts and the greater its relevance to the topic. WordArt ${ }^{\circledR}$ also repeats the most cited words on smaller scales to make the image more robust.

The words found have three focuses: (i) Companies, mentioning elements of the factory, machines, sensors, parts, programmable logic controller (PLCs), robots, among others; (ii) Information Technology, mentioning: software, manufacturing execution system (MES), enterprise resource planning (ERP), Supervisory Control and Data Acquisition (SCADA), among others; and (iii) Characteristics/Factors, showing concepts considered important in Industry 4.0 for respondents: time, cost, integration, standardization, communication, among others. From Table 2 it was possible to organize the interviewees' main ideas and to triage the 91 pages of the transcripts based on the script's five questions (Table 2). That reduced the number of pages to a total of 11 pages containing data considered essential for the creation of the cognitive map - the cognitive map drawn from Figure 3 and transcript responses. 
For the creation of the cognitive map, the topic of the interview was centralized (Industry 4.0) and five clusters were created, one for each question and different colors for clearer visualization and differentiation. The green cluster organized all the answers that relate to question 1: "What do you understand as Industry 4.0?" from the "Definition/Concept" table. The brown cluster replied to question 2: "If a company requested to become 4.0 through steps (due to lack of investment), what would the steps be?" from the "Steps" table. The blue cluster shows the answers to question 3: " What are the minimum technologies that one must have to be able to have a 4.0 industry?" from the "Technologies" table. The orange cluster replied to question 4: "What do you understand about communication between machines?" from the "M2M (machine-to-machine)" table. Finally, the purple cluster sought to answer the questions concerning Brazil, being divided into two parts "Benefits" and "Barriers."

Dotted lines between words within a cluster on the map indicate the existence of a connection. The dotted lines that connect words from different clusters served mainly so that there were no repetitions of words in the cognitive map. The next section, the discussion section, will address the results found in the cognitive map and point directions in the research.

\section{DISCUSSION}

The creation of the cognitive map facilitated the split of the question script into five clusters. The results found in the clusters indicate what the respondents think about the subject Industry 4.0. This made it possible for one, through the literature, to create questions, surveys, and directions about the intervewees' opinions.

Green Cluster - This cluster listed the answers to question 1: "What do you understand as Industry 4.0?". What was evidenced when analyzing the cluster is that most of the respondents have a notion of the term Industry 4.0's meaning. Based on answers such as "integration," "information processing," and "communication", some respondents showed some degree of knowledge in relation to the literature, in which authors bring concepts of cyber-physical systems, digitalization, and Internet of Things (IOT) (Lee et al., 2015; Wollschlaeger et al., 2017; Bartodziej, 2017). These terms relate the words found; it is then necessary to achieve integration of collaborative computational elements to control physical entities to process information. That would lead to cyber-physical systems, being the link of IoT industries (Lee et al., 2015; Colombo et al., 2017; Junior et al., 2017). On the other hand, some respondents were hesitant to answer the

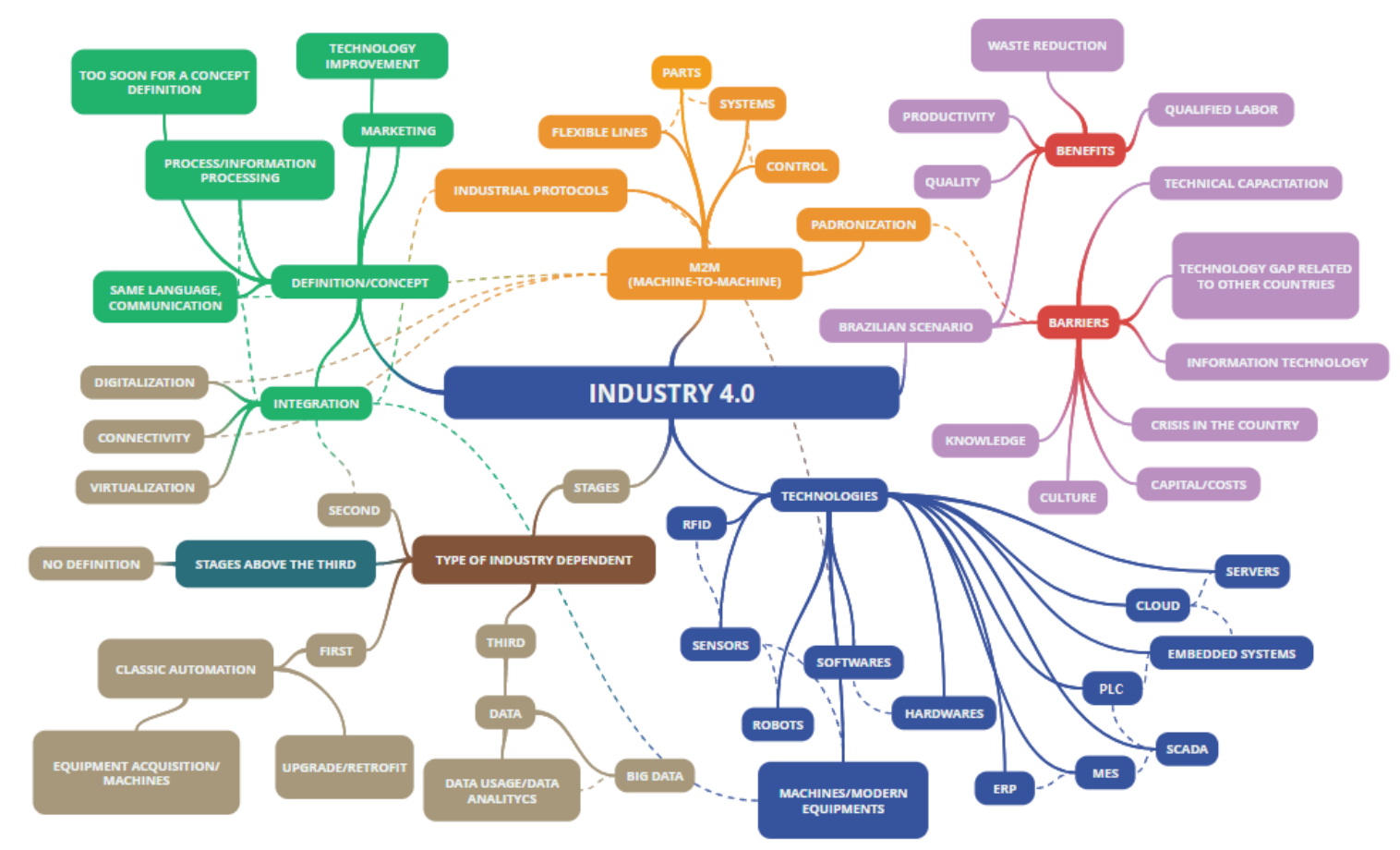

Figure 3. Cognitive Map

Source: The authors. 
question because it is a relatively new term and many authors still discuss the premises and what Industry 4.0 is in its essence (Jazdi, 2014; Lasi et al., 2014; Rüßmann et al., 2015).

It is worth noting that one of the respondents characterized Industry 4.0 as the "technology increase." Although the answer is not inaccurate, it is considered only partially correct because many technologies (cloud, 3D printing, sensors, actuators, among others) exist (Bangemann et al., 2016; Liu and Xu, 2017). What is, in fact, truly new, is its integration, i.e., being able to generate new paths and even new integrative technologies (Brecher et al., 2017). Another question pointed out by the interviewees is that the term Industry 4.0 is a marketing movement created by the German government. According to these interviewees, there is not an Industry 4.0, being Advanced Manufacturing the most correct term to be used, noting what had already been evidenced in the previous theoretical reference. What can be concluded from the responses in the green cluster is that although the term "Industry 4.0" has been in existence since 2011, it still generates doubt when put into question. There is still a need for more studies that address the theme and define Industry 4.0's nature.

Brown cluster - This cluster related the answers to question 2: "If a company requested to become 4.0 through steps (due to lack of investment), what would the steps be?" This was one of the questions interviewees had the most noticeable difficulty answering, which is due to the need for the theme Industry 4.0 to be explored in the literature. Intervewees did not clearly know what the steps are for an industry to become 4.0. It was verified that all the interviewees agreed that it depends on the type of company/industry that seeks to become 4.0. This reflects reports from large consulting companies (McKinsey, BCG, and PwC) that have conducted research on the different industrial segments. From this information, it was possible to trace the first three steps of implementation, analyzing the coherence of the responses.

The interviews allowed an outline of the three initial steps of implementation: (i) classic automation; (ii) integration; and (iii) data. The first step, (i) classic automation, was defined in this way by the interviewees to understand that for a company to become 4.0 it needs a minimum of automated equipment and machines to be connected. Moreover, regarding step (i), two scenarios were verified: (a) those of companies that do not have such equipment/machines, requiring an investment for acquisition; and (b) those of companies that already own such machines and equipment. In both cases there are advantages and disadvantages. For example, in scenario (a), there is a need for a high investment relating to plant automation; however, the equipment and machines that will be purchased may already be able to communicate with one another and will be of the latest generation.
For this, it is enough for the company to put into its planning the acquisition of equipment with the same industrial communication protocol (Faul et al., 2016; Bohuslava et al., 2017). In scenario (b), the machines/equipment that the company already owns might be considered outdated, and therefore not have the same industrial communication protocol because they come from different suppliers. In that case, retrofitting or upgrading them is crucial. This may be difficult or even unfeasible to accomplish, depending on which industrial protocols have been established by manufacturers. Moving from step (i) to classic automation, the interviewees understand that the next step is the integration of these machines and equipment.

Noticeable, step (ii) integration is also one of the answers to question 1 (green cluster). From this step, the concepts of Industry 4.0 are used, where there is a need for integration between machines and equipment so connectivity, digitalization, and virtualization can be achieved (Brettel et al., 2014; Zarte et al., 2016). By integrating machines and equipment through industrial protocols, it is possible to start the vertical integration (Jansen and Cusumano, 2013; Trappey et al., 2017; Ferreira et al., 2016), which, if applied in its entirety, occurs when all links within the organization can communicate with one another (Christmann et al., 2016). In order for this process to be enabled, one can highlight step (iii) data, in which the respondents mentioned Big Data and data analytics. Essentially, this third step would be to analyze and work with the information generated within the company/industry through machine integration.

After the third step the interviewees did not know how to define new steps. It could be appropriate to insert horizontal integration as the next step within this cluster, in which the company would work within the value chain, sharing information with its partners and customers (Zhou et al., 2015). Other steps lack studies in the literature, since until this moment there are no authors mentioning the implementation of steps to create an Industry 4.0.

Blue Cluster - This cluster comprised the answers to question 3: "What are the minimum technologies that one must have in order to have a 4.0 industry?". This was one of the questions respondents considered relatively easy to answer, since the majority of them either have previous work experience with the technologies or prior knowledge of the technologies in the market. All of the interviewees mentioned the need for Radio-Frequency Identification (RFID) or sensors and modern machines/equipment that work with the same industrial protocol to facilitate their integration.

What can be verified is that the main concern related to the companies' manufacturing process. This is due to the intervewees profile, as most of them are either integrator/ supplier of systems and equipments or work in the industry. 
For the production process there is a need for software and hardware and its integration with systems such as ERP, MES, SCADA, and CLPs inside the factory.

The interviewees indicate the need to integrate the technologies of the automation pyramid (Hollender, 2010) so that the machines and equipment can communicate with each other and be able to work in an integrated way. Some interviewees also mention embedded systems and servers as the basis of Industry 4.0, emphasizing that it is nothing beyond an improved 3.0 Industry, since no new technology is presented.

To that end, some interviewees state that the key to integrate systems and processes are robots. These robots are responsible for conducting the activities storage data in the cloud, while, at the same time, this data is available to any collaborator of the factory who wants to access the information. From this question it was possible to confim the information from interviewees through the literature (Rüßmann et al., 2015; Bangemann et al., 2016; Wang et al., 2016). The blue cluster made it possible to raise new research questions: (a) "What new technologies did Industry 4.0 present?"; (b) "Does Industry 4.0 have the capability to provide some new technology?"; and (c) "From now, if any new technology is created, will it be from Industry 4.0?"

Orange Cluster - This cluster concerns the answers to question 4: "What do you understand about communication between machines?" Interviewees prioritized the issue of standardization of industrial protocols for machine integration. Flexible lines were mentioned as one of the objectives from the communication between the machines. These are production lines that can be constantly modified according to current the interest (Gürsoy, 2012).

In the context of Industry 4.0, for example, they could be lines that identify parts, raw materials, or products based on their bar code. They can also achieve that through the use of RFID's for machines or equipment to perform tasks, commands, or different routes from the number or classification of the part, raw material, or product (Wang et al., 2016). From this concept of flexible lines an integrated system within the industry would be feasible, thus making it possible for one to control the productive process. In this manner, this cluster indicated that the interviewees understood the M2M (machine-to-machine) concept within Industry 4.0.

Purple Cluster - This cluster relates to the answers to question 5: "In your understanding, are Brazilian companies prepared for Industry 4.0 or are there difficulties? What are the barriers?" The purple cluster sought to relate answers referring to the interviewees' point of view about the situ- ation in Brazil. In order to accomplish this goal, the answers were divided into two red boxes: (i) Barriers and (ii) Benefits. The main barriers indicated by interviewees are mainly related to the crisis in the country and the lack of investment capital or costs related to technology.

Some of the barriers pointed out (standardization and technical training) by the interviewees had already been reported by the Industrial National Confederation (CNI) in Brazil. The cultural issue was also debated by the interviewees to a considerable extent, mainly because it took place in the country's southern region, where there is a culture of process secrecy, avoinding, therefore, the disclousure of the company's internal information. Another concern raised by the interviewees was the knowledge level of the country's company managers regarding the subject as well as their ability to provide the technologies.

Additionally, the interviewees called attention to the Brazilian technological lag in relation to developed countries such as Germany, the United States, and Japan (Mancilha and Gomes, 2018). However, a question that concerned those interviewed who work in companies that provide systems and equipment is the lack of expertise in information technology, a technical knowledge in high demand. From this concern it became evident that there are several impeding factors in the Brazilian scenario for the implementation of Industry 4.0 and that the country moves slowly towards these changes. The interviewees also specified the main benefits that Industry 4.0 could bring to Brazil, among which industry productivity was the most prominent. Moreover, significant increases in quality were mentioned for industry as well as waste reduction and a greater availability of skilled labor.

Interviewees pointed out that all of these benefits are long-term and that they would not have immediate returns; these factors pose a problem due to the culture of managers prioritizing plans that bring immediate results. A search in the literature produces few studies in English (Jazdi, 2014; Schröder et al., 2015) conducting the theme Industry 4.0 in Brazil. Among such studies there is no contextualization of the Brazilian scenario, as they use only the analysis of the report made by the $\mathrm{CNI}$ as their main reference.

Therefore, several research opportunities were evidenced in the Brazilian context through the interview questions. An analysis of the Brazilian situation would be relevant; equally relevant would be to analyze the main barriers and possible comparisons with models from other countries, including Germany, the United States, and Japan, for the publication of scientific articles that could contribute to the subject within the country. 


\section{CONCLUSION}

This article presented a qualitative approach aiming to answer questions related to the subject Industry 4.0. For this purpose, a script was made with 5 questions considered the most pertinent for the subject, after which people of different profiles were interviewed. Among them were academics, systems and equipment suppliers, and a director of an automobile manufacturing company, all of which possessed a considerable degree of technological knowledge. From the answer transcripts a list of the most cited list of words was obtained. This allowed the creation of the cognitive map from the interviewees' ideas.

The clusters answers of the cognitive map allowed comparisons with the literature and a discussion about the subject Industry 4.0, making it possible to direct and check gaps in the research. Among the discussions presented, the green cluster made it possible to understand that the term "Industry 4.0" has been debated by different authors over the years since its introduction in 2011 at the Hannover Messe technology fair; it also indicated difficiculties still existe regarding the definition of industry 4.0. The brown cluster showed that it is not yet known what all steps of implementation of Industry 4.0 would be and the literature itself confirms this conclusion, due to the lack of studies that present steps or levels of implementation of Industry 4.0 within manufacturing companies.

The blue cluster showed that interviewees have a high degree of knowledge about the technologies currently available for Industry 4.0; in addition, it raised research questions about future technologies. The orange cluster showed that the interviewees had a good understanding about the M2M concept and also presented an interesting discussion about the standardization of industrial protocols that allow the communication between the machines and enable flexible lines within the plant. The purple cluster emphasized Brazil and displayed two very pertinent topics on the subject. The first one presented the barriers that the companies in Brazil can find if they wish to achieve 4.0. The second addressed what would the main long-term be.

The main limitations of the article are found in the subjectivity of the results and also in the scarcity in the literature related to some topics covered in the clusters. As suggestions for future work are the covered questions within the clusters about the subject and also the suggestion for more academic works of international relevance analyzing the situation of Brazil through comparisons with models from other countries such as Germany, United States, or Japan.

\section{REFERENCES}

Andersen, R. E.; Hansen, E. B.; Cerny, D.; Madsen, S.; Pulendralingam, B.; Bøgh, S.; Chrysostomou, D. (2017), "Integration of a Skill-based Collaborative Mobile Robot in a Smart Cyber-physical Environment", Procedia Manufacturing, Vol. 11, pp. 114-123.

Askarpour, M.; Mandrioli, D.; Rossi, M.; Vicentini, F. (2019), "Formal model of human erroneous behavior for safety analysis in collaborative robotics", Robotics and Computer-Integrated Manufacturing, Vol. 57, pp. 465-476.

Bruno, G.; Antonelli, D. (2018), “Dynamic task classification and assignment for the management of human-robot collaborative teams in workcells", The International Journal of Advanced Manufacturing Technology, Vol. 98, No. 9-12, pp. 24152427.

Chi, W.; Liu, J.; Rafii-Tari, H.; Riga, C.; Bicknell, C.; Yang, G-Z. (2018), "Learning-based endovascular navigation through the use of non-rigid registration for collaborative robotic catheterization", International Journal of Computer Assisted Radiology and Surgery, Vol. 13, No. 6, pp. 855-864.

Dalenogare, L. S.; Benitez, G. B.; Ayala, N. F.; Frank, A. G. (2018), "The expected contribution of Industry 4.0 technologies for industrial performance", International Journal of Production Economics, Vol. 204, pp. 383-394.

Dombrowski, U.; Stefanak, T.; Perret, J. (2017), “Interactive Simulation of Human-robot Collaboration Using a Force Feedback Device", Procedia Manufacturing, Vol. 11, pp. 124-131.

Drath, R.; Horch, A. (2014), “Industrie 4.0: Hit or Hype?”, IEEE Industrial Electronics Magazine, Vol. 8, No 2, pp. 56-58.

Eimontaite, I.; Gwilt, I.; Cameron, D.; Aitken, J. M.; Rolph, J.; Mokaram, S.; Law, J. (2018), "Language-free graphical signage improves human performance and reduces anxiety when working collaboratively with robots", The International Journal of Advanced Manufacturing Technology, Vol. 100, No. 1, pp. 5573.

Geissbauer, R.; Vedso, J.; \& Schrauf, S. (2016). “Indústria 4.0: Digitalização como vantagem competitiva no Brasil”, Relatório de pesquisa da PWC group.

Hermann, M.; Pentek, T.; Otto, B. (2016), “Design Principles for Industrie 4.0 Scenarios" 2016 49th Hawaii International Conference on System Sciences (HICSS), Koloa, HI, pp. 39283937.

Hobsbawm, E. J. (1996), The Age of Revolutions: 1789-1848, Vintage Books.

Hopp, W. J.; Spearman, M. L. (2011), Factory Physics, Waveland Press. 
Brazilian Journal of Operations \& Production Management

Volume 16, Número 2, 2019, pp. 192-200

DOI: 10.14488/BJOPM.2019.v16.n2.a3
IIES (2017), Industria 4.0, available from: http://iies.es/eventos/industria-4-0, (access 20 nov. 2017).

Kagermann, H.; Wahlster, W.; Helbig, J. (2013). Recommendations for Implementing the Strategic Initiative INDUSTRIE 4.0, Berlin: Industrie 4.0 Working Group of Acatech.

Khalid, A.; Kirisci, P.; Khan, Z. H.; Ghrairi, Z.; Thoben, K-D.; Pannek, J. (2018), "Security framework for industrial collaborative robotic cyber-physical systems", Computers in Industry, Vol. 97, pp. 132-145.

Lee, J.; Bagheri, B.; Kao, H-A. (2015), “A Cyber-Physical Systems architecture for Industry 4.0-based manufacturing systems", Manufacturing Letters, Vol. 3, pp. 18-23.

Liao, Y.; Deschamps, F.; Loures, E. F. R; Ramos, L. F. P. (2017), "Past, present and future of Industry 4.0 - a systematic literature review and research agenda proposal", International Journal of Production Research, Vol. 55, No. 12, pp. 3609-3629.

Lorenz, M.; Rüßmann, M.; Strack, R.; Lueth, K. L.; \& Bolle, M. (2015), "Man and machine in industry 4.0: How will technology transform the industrial workforce through 2025", The Boston Consulting Group.

Manyika, J.; Chui, M.; Bisson, P.; Woetzel, J.; Dobbs, R.; Bughin, J.; \& Aharon, D. (2015), "Unlocking the Potential of the Internet of Things" McKinsey Global Institute.

Masinga, P.; Campbell, H.; Trimble, J. A. (2015), "A framework for human collaborative robots, operations in South African automotive industry", IEEE International Conference on Industrial Engineering and Engineering Management (IEEM), pp. 1494-1497.

Mendes, N.; Safeea, M.; Neto, P. (2018), “Flexible programming and orchestration of collaborative robotic manufacturing systems", 2018 IEEE 16th International Conference on Industrial Informatics (INDIN), pp. 913-918.

Ministério do Trabalho (2015), “NR-12: Segurança no trabalho em máquinas e equipamentos, Portaria MTb n. 3.214, jun. 1978", available from: http://trabalho.gov.br/images/Documentos/SST/NR/NR12/NR-12atualizada2015II.pdf (access 22 nov. 2017).

Neves, J.; Serrario, D.; Pires, J. R. (2018), “Application of mixed reality in robot manipulator programming", Industrial Robot: An International Journal, Vol. 45, No. 6, pp.784-793.
Pereira, A.; Simonetto, E. O.; Putnik, G.; Castro, H. C. G. A (2018), "How connectivity and search for producers impact production in industry 4.0 networks", Brazilian Journal of Operations and Production Management, Vol. 15, pp. 528-534.

Pereira, G. B.; Santos, A. P. L.; Cleto, M. G. (2018), "Industry 4.0: glitter or gold? A systematic review", Brazilian Journal of Operations and Production Management, Vol. 15, pp. 247-253.

Sadik, A. R.; Taramov, A.; Urban, B. (2017), “Optimization of tasks scheduling in cooperative robotics manufacturing via johnson's algorithm case-study: One collaborative robot in cooperation with two workers", 2017 IEEE Conference on Systems, Process and Control (ICSPC), pp. 36-41.

Schuh, G.; Anderl, R.; Gausemeier, J.; Hompel, M.; Wahlster, W. (2017), Industrie 4.0 Maturity Index, available from: https:// en.acatech.de/wp-content/uploads/sites/6/2018/03/acatech_ STUDIE_Maturity_Index_eng_WEB.pdf (access 24 oct. 2017).

Schumacher, A.; Erol, S.; Sihn, W. (2016), “A maturity model for assessing Industry 4.0 readiness and maturity of manufacturing enterprises", Procedia CIRP, Vol. 52, pp. 161- 166.

Schwab, K. (2017), The Fourth Industrial Revolution, Crown Business.

Scopus (2019), available from: www.scopus.com (access 21 jan. 2019).

Vasconez, J. P.; Kantor, G. A.; Cheein, F. A. A. (2019), “Human-robot interaction in agriculture: $A$ survey and current challenges", Biosystems Engineering, Vol. 179, pp. 35-48.

Vazquez, A. N.; Jabi, W. (2015), “A Collaborative Approach to Digital Fabrication: A Case Study for the Design and Production of Concrete 'Pop-up' Structures", International Journal of Architectural Computing, Vol. 13, no. 2, pp. 195-216.

Vysocky, A.; Novak, P. (2016), “Human-Robot Collaboration in Industry", Science Journal, pp. 903-906.

Yin, Y.; Stecke, K. E.; Li, D. (2018), "The evolution of production systems from Industry 2.0 through Industry 4.0", International Journal of Production Research, Vol. 56, no. 1-2, pp. 848861.

Zhou, Z.; Xie, S.; Chen, D. (2012), Fundamentals of Digital Manufacturing Science, Springer.

Received: 14 Dec 2018

Approved: 06 Apr 2019

DOI: 10.14488/BJOPM.2019.v16.n2.a3

How to cite: Benitez, G. G.; Lima, MJRF; Lerman, L. V. et al. (2019), “Understanding Industry 4.0: Definitions and insights from a cognitive map analysis", Brazilian Journal of Operations \& Production Management, Vol. 16, No. 2, pp. 192-200, available from: https://bjopm.emnuvens.com.br/bjopm/article/view/677 (access year month day). 